\section{Lipid Content and Fatty Acids of Pecan Pollen}

\author{
Tommy E. Thompson \\ Pecan Genetics and Breeding Research, Agricultural Research Service, U.S. \\ Department of Agriculture, Route 2, Box 133, Somerville, TX 77879
}

\author{
Samuel D. Senter ${ }^{2}$ \\ Richard B. Russell Agricultural Research Center, Agricultural Research \\ Service, U.S. Department of Agriculture, P.O. Box 5677, Athens, GA 30613 \\ L.J. Grauke ${ }^{3}$ \\ Pecan Genetics and Breeding Research, Agricultural Research Service,. U.S. \\ Department of Agriculture, Route 2, Box 133, Somerville, TX 77879
}

Additional index words. Carya illinoinensis

\begin{abstract}
Pollen from five cultivars of pecans [Carya illinoinensis (Wangenh.) K. Koch] was analyzed for cytoplasmic lipid classes and constituent fatty acids. Lipid classes in all cultivars included free fatty acids, triglycerides, and the phosphatide of inositol, serine, choline, glycerol, and ethanolamine. Triglycerides were the predominant class of lipids in all cultivars analyzed. Gas chromatography and mass spectral analysis were used to identify and quantify the fatty acids, which included palmitic, stearic, oleic, linoleic, and linolenic. Quantities of individual and total fatty acids varied greatly and were influenced significantly by cultivar, year, and location, as well as by interactions of main effects The percent composition of individual fatty acids was remarkably stable, despite wide variation in quantities of fatty acids. Therefore, pollen fatty acid ratios may be a valuable measure of taxonomic relationship across Carya sp. Total fatty acids varied from $\mathbf{2 . 5 3 \%}$ to $0.25 \%$ of dry weight. Variability in stored energy in the form of lipids may affect orchard production.
\end{abstract}

There are two lipid domains in the pollen grains of flowering plants: 1) the external lipids of the pollen coat, commonly referred to as "pollenkitt"; and 2) the internal cytoplasmic lipids, presumed to be the products of the haploid genome (Knox, 1984). The external lipoidal coating present in entomophilous species is produced in the tapetal cells that line the anther cavity and is transferred to the surface of the pollen grain late in pollen development. In anemophilous species, such as pecan, the pollen coat remains in the anther locule at pollen dispersal (Yates and Sparks, 1992). In cytological studies of developing pecan pollen, Yates and Sparks (1992) found that cytoplasmic lipids first appear at about the time that anthers first become visible.

Lipid composition in the pollen of some species has been reported (Evans et al., 1987), but no information exists on pecan pollen. There is tremendous variability in in vitro pollen germination rates, even from the same samples under identical conditions. Relating pecan pollen staining to germination is even

\footnotetext{
Received for publication 29 Apr. 1993. Accepted for publication 16 July 1993. Reference to a company or product name does not imply approval or recommendation by the U.S. Dept. of Agriculture. The cost of publishing this paper was defrayed in part by the payment of page charges. Under postal regulations, this paper therefore must be hereby marked advertisement solely to indicate this fact. ${ }^{1}$ Research Geneticist.

${ }^{2}$ Research Food Technologist.

${ }^{3}$ Research Horticulturist.
}

less reliable. We hypothesized that pecan pollen germination may be related to stored energy levels.

The objectives of this study were to identify the lipid classes and to determine the influence of cultivar, year, and orchard location on the quantity of fatty acids in pecan pollen.

\section{Materials and Methods}

Pollen source. Pollen was collected at Brownwood and College Station, Texas, from trees maintained by the Pecan Genetics and Breeding Program, Agricultural Research Service/U.S. Dept. of Agriculture (USDA). In 1991, 'Osage' and 'Pawnee' were collected at Brownwood; and 'Desirable', 'Osage', 'Wichita', and 'Pawnee' pollen samples were collected at College Station. Pollen from these latter four cultivars plus 'Stuart' was collected at both locations in 1992. Collections were from uniformly young ( $<10$ years old), comparably managed trees. Pollen collections from a cultivar may represent an individual tree, or be a composite of up to four trees. Each cultivar represents a single pecan clone.

Catkins were collected at maturity, held at $68 \mathrm{C}$ overnight to allow pollen release, and pollen was separated from plant debris by sieving. Samples collected in 1991 were held at $-10 \mathrm{C}$ until May 1992, so that samples from both years could be analyzed at the same time. Samples (10 g each) were shipped under refrigeration to the Richard B. Russell Research Center, USDA, Athens, Ga., for analysis.
Samples were lyophilized and stored at -20C in sealed vials over desiccant until analyzed.

Lipid extraction. Aliquots $(1 \mathrm{~g})$ of the freeze-dried pollen were placed in screwcapped tubes with $20 \mathrm{ml}$ of 2 chloroform : 1 methanol (v/v) and shaken with a wrist-action shaker for $24 \mathrm{~h}$. Extracts were clarified by centrifugation for $10 \mathrm{~min}$ at $16,000 \times \mathrm{g}$, after which solvents were removed with a rotary evaporator $(50 \mathrm{C}, 3.32 \mathrm{kpa})$. Extracts were resuspended in $3 \mathrm{n}-\mathrm{d}$ of hexane and stored in sealed vials under $\mathrm{N}_{2}$ at $2 \mathrm{C}$.

Lipid classes. The crude extracts $(3 \mu \mathrm{l}$ each) were applied as a single spot to $20-\mathrm{cm}$, high-performance, silica gel thin-layer chromatography (TLC) plates (Fisher Scientific, Pittsburgh). The plates were developed for 14 $\mathrm{cm}$ with $\mathrm{CHCl}_{3}$, dried, and then redeveloped for $10 \mathrm{~cm}$ with $65 \mathrm{CHCl}_{3}: 30 \mathrm{CH}_{3} \mathrm{OH}: 3$ $\mathrm{NH}_{4} \mathrm{OH}$ (Kates, 1972). After drying, lipids were visualized by spraying with $25 \% \mathrm{H}_{2} \mathrm{SO}_{4}$ and heating at $150 \mathrm{C}$ for $20 \mathrm{~min}$. Individual lipid classes were identified by comparative $R_{r}$ values and codevelopment with authentic standards (Matreya, Pleasant Gap, Pa.).

Fatty acid analysis. Two milliliters of crude extract were taken to dryness with a stream of dry $\mathrm{N}_{2}$, resuspended in $3 \mathrm{ml}$ of $0.5 \mathrm{~N} \mathrm{NaOH}$ in $100 \%$ methanol (20 g.liter $\left.{ }^{-1}\right)$, then saponified by heating for $5 \mathrm{~min}$ at $85 \mathrm{C}$. Sodium salts of the fatty acids were dissolved in $1 \mathrm{ml}$ of distilled $\mathrm{H}_{2} \mathrm{O}$ with shaking, and the suspension was washed six times with $5 \mathrm{ml}$ of hexane each time. After removal of nonsaponifiable materials, free fatty acids (FFA) were formed by acidification with $2 \mathrm{ml}$ of $1.5 \mathrm{NHC1}$. FFA were extracted with hexane, dried with a stream of $\mathrm{N}_{2}$, and the methyl esters were then formed with $3 \mathrm{ml}$ of $14 \%$ boron trifluoride-methanol (Sigma, St. Louis) by heating at $85 \mathrm{C}$ for $5 \mathrm{~min}$. Two milliliters of saturated aqueous $\mathrm{NaCl}$ and $1 \mathrm{ml}$ of heptane, containing $6 \mathrm{mg}$ methyl heptadecanoic (margaric) acid as an internal standard, were added to the solution, and the esters were partitioned into the heptane by shaking. Analysis of the methyl esters was performed with a Perkin-Elmer (Norwalk, Corm.) Sigma 300 capillary gas chromatography equipped with a 60:1 split injector. Data were collated with a Perkin-Elmer Omega 2 Analytical Workstation. Esters were separated with a $30 \mathrm{~m} \times 0.32-\mathrm{mm}$ (id.) Silar $10 \mathrm{C}$ fused silica column using $41 \mathrm{kpa} \mathrm{He}$ as the carrier gas. The column oven was programmed from 160 to $220 \mathrm{C}$ at $4 \mathrm{C} / \mathrm{min}$. Methyl esters of the fatty acids were identified by comparison of retention times with standards and by mass spectral analysis with an Extrel Model C50-400 quadrapole MS operated as described previously (Horvat et al., 1990). Results of duplicate analysis of the replicated extractions were averaged, and results expressed as milligrams fatty acid per gram of pollen (dry weight).

Statistical analysis. The General Linear Models (GLM) procedure of the Statistical Analysis System (SAS Institute, 1985) was used to determine correlation coefficients and the influence of cultivar, location, and year on fatty acid quantity and type. Least-square means were separated at $\boldsymbol{P}<\mathbf{0 . 0 5}$, using paired t tests. 


\section{Breeding, Cultivars, Rootstocks, \& Germplasm Resources}

\section{Results and Discussion}

Lipid classes isolated and identified by TLC analysis of extracts from all cultivars included the phosphatide of inositol (PI), senne (PS), choline (PC), glycerol (PG), ethanolamine (PE), FFA, triglycerides (TG) (Fig. 1), and traces of phosphatidic acid (not indicated). The predominant class of lipids in all cultivars was TG, followed by PC and PE. Quantitative data were not obtained on the lipid classes; however, differences were apparent, as evidenced by quantitative differences in the fatty acid analyses.

Fatty acids present in pollen from all cultivars were palmitic (16:0), stearic (18:0), oleic (18:1), linoleic (18:2), and linolenic (18:3) (Fig. 2). The quantity of an individual fatty acid was significantly correlated with quantities of all other fatty acids in that sample (Table 1). Stearic was the least correlated with the other fatty acids and the total. The reason for this greater variability is not known. The high level of composition stability across great differences in total fatty acid quantities makes this profile potentially useful in Carya sp. identification and the study of species differences.

The percentage of each acid in relation to total fatty acids, averaged over years, cultivars, and locations, was: palmitic, 25.190; stearic, $2.5 \%$; oleic, $16.6 \%$; linoleic, $27.4 \%$; and linolenic, $28.4 \%$. Saturated fatty acids (palmitic and stearic acids) accounted for $28 \%$ of the total, while unsaturated fatty acids accounted for $72 \%$ of the total.

When data were analyzed for the influence of cultivar, year, and orchard location on percent composition of individual fatty acids (Table 2), the percent palmitic acid was not affected by any test variable or interaction. The percentage of stearic acid was significantly higher in 1991 than 1992, and there was a significant interaction of cultivars with years, due primarily to variation of 'Osage' across years. The percent oleic acid showed significant differences between cultivars, with 'Pawnee' having the highest mean percent $(17.3 \%)$ and 'Desirable' the lowest (15.570). The percent oleic acid was influenced by the interaction of cultivar and location: 'Pawnee' at Brownwood had a significantly higher percent oleic acid content $(17.9 \%)$ than 'Pawnee' at College Station (16.6\%), while other cultivars were unchanged by location. Percent oleic acid also showed significant interaction of year, cultivar, and location, attributable in large part to the very low percentage of oleic acid $(14.3 \%)$ in the 1992 samples of 'Desirable' from Brownwood and the high percentage of oleic acid (18.5\%) in the 1991 samples of 'Osage' from College Station. The percentages of linoleic acid were influenced by year and cultivar (Table 2), without other significant interactions.

Samples varied widely in the quantity of individual and total fatty acids, with some samples having several times the quantity found in other samples of the same cultivar (Table 3). For example, 'Pawnee' pollen collected in 1991 at Brownwood had a higher fatty acid

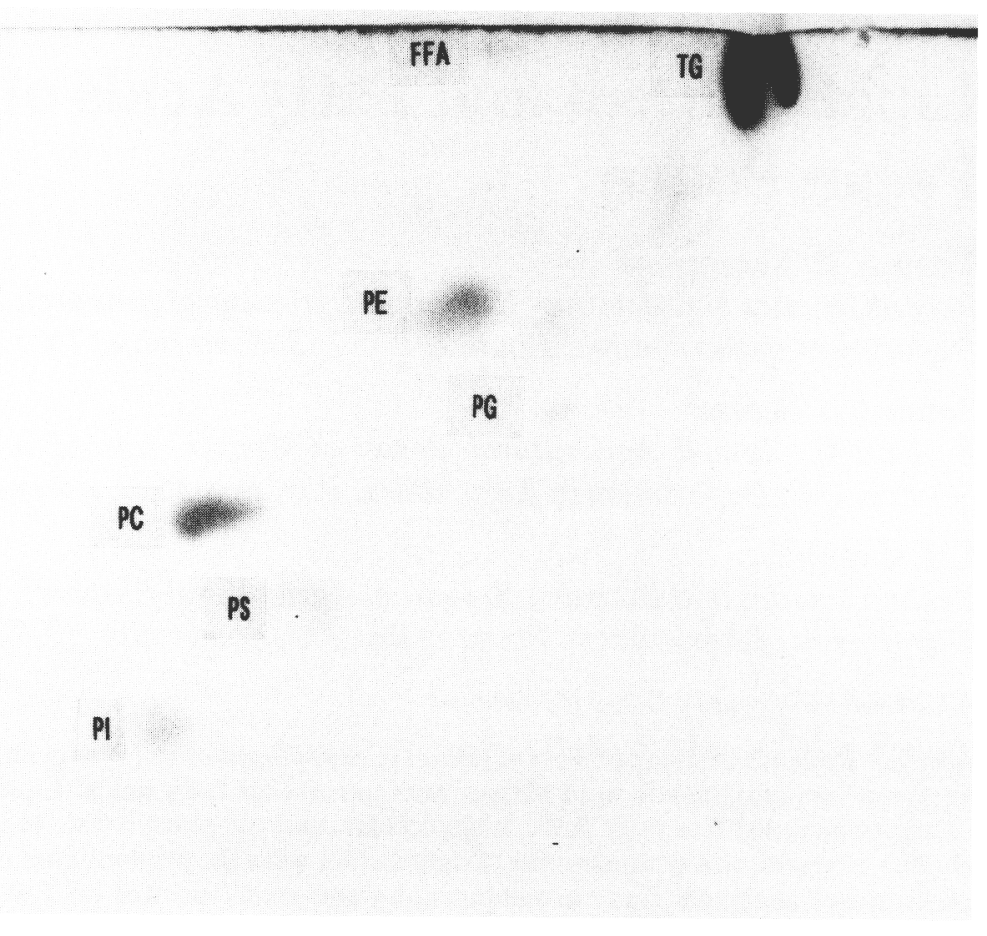

Fig. 1.Separationoflipidclassesinpecanpollenbyhigh-resolution silica gel-G thin-layer chromatography. Solvent $1, \mathrm{CHCl}_{3}$; solvent 2, $65 \mathrm{CHCl}_{3}: 30 \mathrm{MeOH}: 3 \mathrm{NH}_{4} \mathrm{OH}$. PI = phosphatidyl inositol, PS = phosphatidyl serine, $\mathrm{PC}=$ phosphatidyl choline, $\mathrm{PG}=$ phosphatidyl glycerol, $\mathrm{PE}=$ phosphatidyl ethanolamine, $\mathrm{FFA}=$ free fatty acids, $\mathrm{TG}=$ triglycerides .

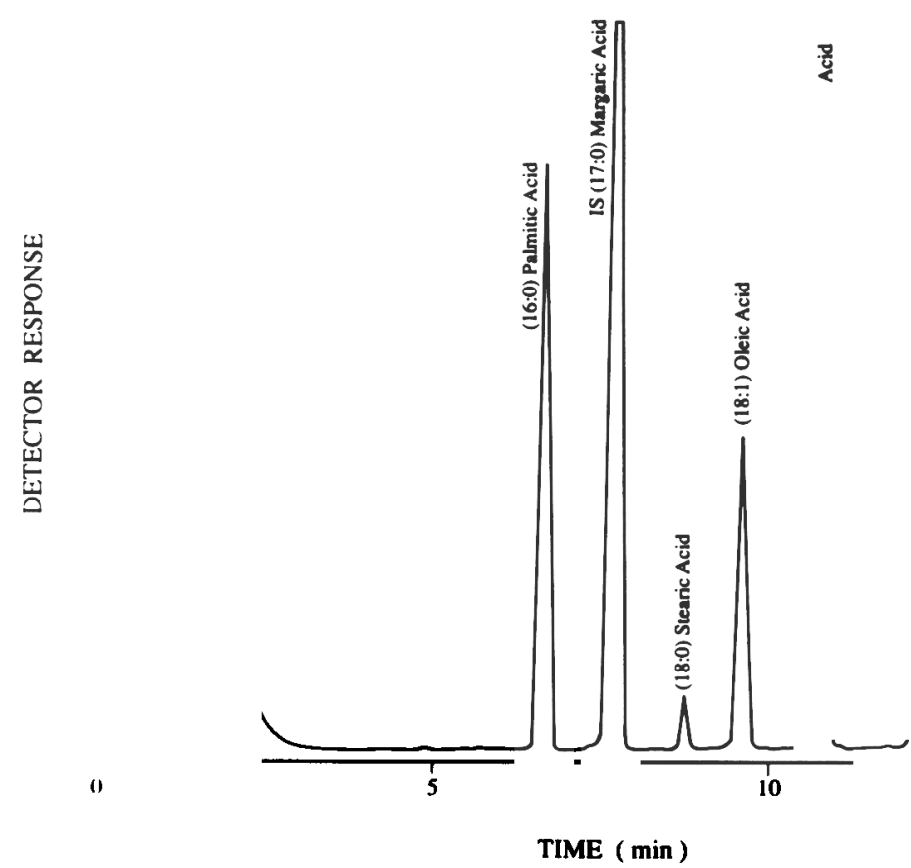

15

Fig. 2. Gas chromatographic separation of methyl esters of fatty acids in pecan pollen on a $30 \mathrm{~m} \times 25-\mathrm{mm}$ Silar 10C column. Oven temperature, $160-220 \mathrm{C}$ at $4 \mathrm{C} / \mathrm{min}$; He carrier gas at $41 \mathrm{kPa}$.

Table1.Correlationcoefficients $(r)$ forquantities of individual and total fatty acids for cultivars, years, and locations. All values significant at $P \leq 0.0001$.

\begin{tabular}{llcccc}
\hline \hline & \multicolumn{4}{c}{ Fatty acid } \\
\cline { 2 - 6 } Fatty acid & Stearic & Oleic & Linoleic & Linolenic & Total \\
\hline Palmitic & 0.913 & 0.980 & 0.981 & 0.981 & 0.990 \\
Stearic & & 0.934 & 0.931 & 0.928 & 0.934 \\
Oleic & & 0.998 & 0.996 & 0.998 \\
Linoleic & & & 0.996 & 0.998 \\
Linolenic & & & & 0.997 \\
\hline
\end{tabular}


Table 2. The influence of year, location $(\mathrm{BW}=$ Brownwood and CS = College Station, Texas), and cultivar on quantity and percent composition of fatty acids in pecan pollen from young trees.

\begin{tabular}{|c|c|c|c|c|c|c|c|c|c|c|c|}
\hline \multirow{3}{*}{$\begin{array}{l}\text { Main } \\
\text { effects }\end{array}$} & \multicolumn{11}{|c|}{ Fatty acid } \\
\hline & \multicolumn{2}{|c|}{ Palmitic } & \multicolumn{2}{|c|}{ Stearic } & \multicolumn{2}{|c|}{ Oleic } & \multicolumn{2}{|c|}{ Linoleic } & \multicolumn{2}{|c|}{ Linolenic } & \multirow[b]{2}{*}{ Total } \\
\hline & $\mathrm{mg} \cdot \mathrm{g}^{-1}$ & $\%$ & $\mathrm{mg} \cdot \mathrm{g}^{-1}$ & $\%$ & $\mathrm{mg} \cdot \mathrm{g}^{-1}$ & $\%$ & $\mathrm{mg} \cdot \mathrm{g}^{-1}$ & $\%$ & $\mathrm{mg} \cdot \mathrm{g}^{-1}$ & $\%$ & \\
\hline 1991 & $2.37 \mathrm{a}^{2}$ & $25.6 \mathrm{a}$ & $0.28 \mathrm{a}$ & $3.3 \mathrm{a}$ & $1.69 \mathrm{a}$ & $16.9 \mathrm{a}$ & $2.69 \mathrm{a}$ & $27.6 \mathrm{a}$ & $2.75 \mathrm{a}$ & $28.6 \mathrm{a}$ & $9.77 \mathrm{a}$ \\
\hline 1992 & $1.42 \mathrm{~b}$ & $24.4 \mathrm{a}$ & $0.13 b$ & $2.1 \mathrm{~b}$ & $0.92 \mathrm{~b}$ & $16.4 \mathrm{a}$ & $1.53 \mathrm{~b}$ & $27.0 \mathrm{~b}$ & $1.53 \mathrm{~b}$ & $28.3 \mathrm{a}$ & $5.54 \mathrm{~b}$ \\
\hline BW & $2.04 \mathrm{a}$ & $25.2 \mathrm{a}$ & $0.20 \mathrm{a}$ & $2.2 \mathrm{a}$ & $1.39 \mathrm{a}$ & $16.5 \mathrm{a}$ & $2.27 \mathrm{a}$ & $27.7 \mathrm{a}$ & $2.25 \mathrm{a}$ & $28.4 \mathrm{a}$ & $8.15 \mathrm{a}$ \\
\hline $\mathrm{CS}$ & $1.58 \mathrm{~b}$ & $25.1 \mathrm{a}$ & $0.18 \mathrm{~b}$ & $2.8 \mathrm{a}$ & $1.07 \mathrm{~b}$ & $16.7 \mathrm{a}$ & $1.73 \mathrm{~b}$ & $27.1 \mathrm{a}$ & $1.78 \mathrm{~b}$ & $28.4 \mathrm{a}$ & $6.34 \mathrm{~b}$ \\
\hline Pawnee & $3.48 \mathrm{a}$ & $25.3 \mathrm{a}$ & $0.36 \mathrm{a}$ & $2.7 \mathrm{a}$ & $2.41 \mathrm{a}$ & $17.3 \mathrm{a}$ & $3.80 \mathrm{a}$ & $27.3 \mathrm{~b}$ & $3.78 \mathrm{a}$ & $27.4 \mathrm{~b}$ & $13.83 \mathrm{a}$ \\
\hline $\mathrm{W}$ i c h i t a & $1.57 \mathrm{~b}$ & $25.5 \mathrm{a}$ & $0.19 b$ & $3.0 \mathrm{a}$ & $1.02 \mathrm{~b}$ & $16.6 \mathrm{~b}$ & $1.69 \mathrm{~b}$ & $27.5 \mathrm{~b}$ & $1.69 \mathrm{~b}$ & $27.4 \mathrm{~b}$ & $6.16 \mathrm{~b}$ \\
\hline Osage & $1.40 \mathrm{c}$ & $24.7 \mathrm{a}$ & $0.14 \mathrm{c}$ & $2.0 \mathrm{a}$ & $0.99 \mathrm{c}$ & $16.6 \mathrm{~b}$ & $1.69 \mathrm{~b}$ & $28.7 \mathrm{a}$ & $1.64 \mathrm{c}$ & $28.1 \mathrm{~b}$ & $5.86 \mathrm{C}$ \\
\hline Desirable & $0.88 \mathrm{~d}$ & $25.8 \mathrm{a}$ & $0.11 \mathrm{~d}$ & $2.9 \mathrm{a}$ & $0.53 \mathrm{e}$ & $15.5 \mathrm{c}$ & $0.87 \mathrm{C}$ & $25.5 \mathrm{C}$ & $1.02 \mathrm{~d}$ & $30.2 \mathrm{a}$ & $3.42 \mathrm{~d}$ \\
\hline Stuart & $0.80 \mathrm{~d}$ & $24.1 \mathrm{a}$ & $0.07 \mathrm{e}$ & $2.0 \mathrm{a}$ & $0.55 \mathrm{~d}$ & $16.8 \mathrm{ab}$ & $0.90 \mathrm{c}$ & $27.3 \mathrm{~b}$ & $0.98 \mathrm{e}$ & $29.9 \mathrm{a}$ & $3.30 \mathrm{~d}$ \\
\hline
\end{tabular}

'Within columns, and within years, locations, and cultivars, mean separation according to paired $t$ tests $(P \leq 0.05)$ using least-square means.

Table 3. Patterns of variability in quantities of fatty acids ( $\left.\mathrm{mg}_{\bullet} \mathrm{g}^{-1}\right)$ as influenced by cultivar, year, and location $(\mathrm{BW}=$ Brownwood and $\mathrm{CS}=$ College Station, Texas).

\begin{tabular}{lcccccccc}
\hline & & \multicolumn{5}{c}{ Fattyacid } \\
\cline { 3 - 8 } Cultivar & Year & Location & Palmitic & Stearic & Oleic & Linoleic & Linolenic & Total \\
\hline Desirable & 1991 & CS & 0.91 & 0.21 & 0.58 & 0.89 & 1.10 & 3.70 \\
& 1992 & BW & 0.80 & 0.03 & 0.43 & 0.78 & 0.97 & 3.01 \\
& & CS & 0.94 & 0.09 & 0.59 & 1.94 & 1.00 & 3.55 \\
Osage & 1991 & BW & 1.41 & 0.15 & 0.88 & 1.53 & 1.50 & 5.48 \\
& & CS & 2.00 & 0.30 & 1.78 & 2.87 & 2.72 & 9.66 \\
& \multirow{2}{*}{1992} & BW & 0.74 & 0.04 & 0.45 & 0.80 & 0.79 & 2.78 \\
& & CS & 1.44 & 0.08 & 0.87 & 1.56 & 1.55 & 5.50 \\
Pawnee & 1991 & BW & 6.23 & 6.61 & 4.50 & 7.04 & 6.93 & 25.31 \\
& & CS & 2.23 & 0.23 & 1.42 & 2.26 & 2.64 & 8.78 \\
& 1992 & BW & 1.98 & 0.22 & 1.42 & 2.23 & 2.02 & 7.88 \\
& & CS & 3.47 & 0.37 & 2.31 & 3.68 & 3.52 & 13.35 \\
Stuart & 1992 & BW & 0.96 & 0.12 & 0.68 & 1.12 & 1.20 & 4.07 \\
& & CS & 0.65 & 0.03 & 0.42 & 0.68 & 0.76 & 2.53 \\
Wichita & 1991 & CS & 1.45 & 0.18 & 0.98 & 1.52 & 1.61 & 5.73 \\
& 1992 & BW & 2.16 & 0.26 & 1.36 & 2.36 & 2.38 & 8.52 \\
& & CS & 1.09 & 0.12 & 0.70 & 1.20 & 1.10 & 4.22 \\
\hline
\end{tabular}

concentration than that collected at College Station; while in 1992, the reverse was true. Conversely, 'Osage' pollen collected in 1991 at Brownwood contained less fatty acid than that collected at College Station, with the same pattern in 1992.

Fatty acids identified in pecan pollen in the current study are the same as in nuts of trees of the genus Carya (Stone et rd., 1969). However, the relative amounts of constituent fatty acids in pollen are much different than that of the nuts. Likewise; the rapeseed (Brassica napus L.) pollen and seed are dissimilar in the relative amounts of fatty acids (Evans et al., 1987). Linolenic, linoleic, and palmitic acids

ted all pecan pollen san while oleic acid is the predominant fatty acid in nuts of the genus,

Within cultivar, variability in pollen fatty acid content may be related to crop load. The alternating pattern of fatty acid content in 'Pawnee' from Brownwood, in opposite cycle of an alternating pattern in 'Pawnee' from College Station, might be explained by alternating patterns of yield between the two locations.

This research provides information concerning the lipid composition of pecan pollen. Triglycerides, the predominant lipid class, were variable in quantity across cultivars, years. and locations. Triglyceride content in the pollen may influence the ability of pollen to germinate or effect fruit set. Thus, variability in pollen fatty acid content between cultivars may be a valuable indicator of pollinizer performance and may possibly explain pollination failure in orchards when pollen quantity seemed sufficient.

\section{Literature Cited}

Evans, D.E.,N.E. Rothnie,M.V. Pahner,D.G. Burke, J.P. Sang, R.B. Knox, E.G. Williams, E.P. Hilliard, and P.A. Salisbury. 1987. Comparative analysis of fatty acids in pollen and seed of rapeseed. Photochemistry 26:(7):1895-1897.

Horvat, R.J., G.W. Chapman, Jr., J.A. Robertson, F.I. Meredith, R. Scorza, A.M. Callahan, and P. Morgens. 1990. Comparison of the volatile compounds from several commercial peach cultivars. J. Agr. Food Chem. 28:234-237.

Kates, M. 1972. Techniques of lipidology. Isolation, analysis, and identification of lipids. Elsevier, New York.
Knox, R.B. 1984. The pollen grain, p. 197-271. In: B.M. Johri (cd.). Embryology of the angiosperm. Springer-Verlag, New York.

SAS Institute. 1985. Guide for personal computers. SAS Institute Inc., Cary, N.C.

Stone, D. E., G.A. Adrouny, and R.H. Flake. 1969. New World Juglandaceae. II. Hickory nut oils, phenetic similarities, and evolutionary implications in the genus Carya. Amer. J. Bet. 56:928935.

Yates, I.E. and D. Sparks. 1992. External morphological characteristic for periods during pecan microspore and pollen differentiation. J. Amer. Soc. Hort. Sci. 117:190-196. 